\title{
Dealing with Healing: By Novel Biologic Dressing
}

\section{Dr. Nikita B. Rathi ${ }^{1 *}$, Dr. Simran R.Parwani ${ }^{2}$, Dr. Minal N. Ganvir ${ }^{3}$, Dr. Abhay P. Kolte ${ }^{4}$, Dr. Shilpa P. Wasu ${ }^{5}$, Dr. Shruti S.} Wankhade $^{6}$

${ }^{1}$ Post graduate student (3rd year), Department of Periodontology V.Y.W.S. Dental College and Hospital, Amravati, Maharashtra, India ${ }^{2}$ Professor and Head of Department Department of Periodontology V.Y.W.S. Dental College and Hospital, Amravati, Maharashtra, India ${ }^{3}$ Post graduate student (2nd year) Department of Periodontology V.Y.W.S. Dental College and Hospital, Amravati, Maharashtra, India ${ }^{4}$ Professor and Head of Department Department of Periodontology VSPM Dental College and Research Centre, Nagpur, Maharashtra, India ${ }^{5,}$,Lecturer Department of Periodontology, V.Y.W.S. Dental College and Hospital, Amravati, Maharashtra, India

DOI: $10.36347 / \mathrm{sajb} .2021 . v 09 \mathrm{i} 03.006$

| Received: 27.02.2021 | Accepted: 17.03.2021 | Published: 28.03.2021

*Corresponding author: Dr. Nikita Bhagwandas Rathi

Abstract

Original Research Article

Free gingival graft (FGG) continues to be most common and ideal procedure for the treatment of mucogingival problems. Amniotic membrane (AM) has shown promising results in context to healing and patients comfort in various treatment modalities like local drug delivery, after vestibuloplasty, treatment of periodontal osseous defects, gingival recessions and furcation defects but its efficacy in covering palatal wound has not yet been tested so the aim of the present study was to evaluate the effectiveness of AM assisted healing as against natural healing of palatal wound after free gingival graft retrieval at different time intervals. In this randomized controlled trial 10 patients requiring treatment with FGG were selected. Palatal donor sites were randomly assigned ( $n=5$ in each group) to experience either AM assisted healing (group A) or natural healing (group B). Healing at donor site was evaluated using Marini Early Wound Healing Score (EHS) and pain score by Wong and Baker Faces Scale (WBFS). Data were assessed and recorded at one, two and three weeks post-operatively. This prospective study showed statistically significant differences between test and control groups in terms of post-operative re-epithelization, inflammation, haemostasis and pain scores. Amniotic Membrane provides excellent predictability and reduction in inflammatory and pain scores resulting in better wound healing when used as periodontal dressing material as compared to natural healing in palatal free gingival graft wounds. Key words- Free gingival graft, amniotic membrane, biological dressing, early wound healing scores, pain scores, palatal wounds.

Copyright (C) 2021 The Author(s): This is an open-access article distributed under the terms of the Creative Commons Attribution 4.0 International License (CC BY-NC 4.0) which permits unrestricted use, distribution, and reproduction in any medium for non-commercial use provided the original author and source are credited.

\section{INTRODUCTION}

Free autografts have been considered as the "gold standard" for treatment of mucogingival problems as they provide high predictability, relative ease of manipulation and superior aesthetics over other treatment options. Due to the anatomical advantages and ideal tissue thickness, palatal mucosa in the premolar region is considered as optimal donor region [1].

Healing process involved at donor site proceeds by secondary intention or "Granulating in" and takes about 2-4 weeks depending on the width and thickness of the tissue removed. Although the post-operative response at the donor site is uneventful, many-a-times patients suffer traumatic and post-operative discomfort, pain, necrosis, occasional bleeding and/or delayed healing [2]. Considering these pitfalls, a variety of periodontal dressing has been used to reduce post-operative complications and to assist healing [3].
One such novel membrane with greater predictability, ease of use and great magnitude of efficacy is amniotic membrane. It is a composite membrane consisting of pluripotent cellular elements which possess the ability of differentiation to other cellular elements of periodontium embedded in a semi-permeable membranous structure [4]. It contains growth factors that may assist in the formation of granulation tissue by stimulating fibroblast growth and proliferation and aid in neovascularisation [5]. It has an ability to form an early physiologic "seal" with the host tissue preventing bacterial contamination and infection [6].

No study is reported till date in the literature using Amniotic membrane as healing material for palatal wound after FGG retrieval. Furthermore, no study has been published in literature till date mentioning the problems with natural healing of palatal wounds after FGG harvest or with data on prospective patient outcome, FGG postoperative experiences or healing at 
the donor site. Therefore, the purpose of this study was to compare the effects of Amniotic Membrane (AM) assisted healing as against natural healing of palatal wounds after free gingival graft retrieval at different time intervals.

\section{MATERIALS AND METHODS \\ Study design and population}

This human clinical trial was a pilot study with prospective, randomized design. This pilot study design included 10 patients ( 6 male and 4 female) of age group 20-45 years requiring free gingival grafting for periodontal plastic surgery who were randomly divided into group A and group B consisting of 5 patients each by flip coin method in group a patients were treated with AM (obtained from Tata Memorial Hospital $\{\mathrm{TMH}\}$ Tissue Bank) along with acrylic stent and of group B only with periodontal pack and acrylic stent.

Inclusion Criteria were good Simplified Oral Hygiene Index score with no inflammation at the recipient area. Periodontitis patients with true pockets, positive history of alcoholism or addiction, current tobacco smokers/chewers, subjects with abnormal bleeding/clotting time, allergy to impression or acrylic stent (template) material, severe gag reflex preventing maxillary impression making were excluded from the study.

The total duration of the study was 21 days from the day of the surgical procedure. Case history proforma was filled for all participants including all pre and post-operative parameters. No information was given to the patients and other investigators about which group the participants were assigned and extreme care was taken to preserve blinding during whole study period.

\section{Surgical Technique}

10 patients with gingival recession, decreased width of attached gingiva or shallow vestibule was treated by a Classic technique of Free Gingival Graft retrieval. Before surgery, impression of palatal region was made to prepare a surgical stent designed for the donor area protection. Local anesthesia was given and FGG was harvested from the palate as follows: the donor site was extended from the distal line angle of the canine to the mesial line angle of the maxillary first molar. The most coronal horizontal incision, $15 \mathrm{~mm}$ long, was made and $2 \mathrm{~mm}$ apical from the gingival margin; a second horizontal incision of the same length was drawn $8 \mathrm{~mm}$ away from the first, in a more apical position. Two vertical incisions were made to join the ends of the horizontal incisions and to delimitate the graft area. A rectangular-shaped partial-thickness incision was drawn to obtain a graft of 1 to $1.2 \mathrm{~mm}$ in thickness. After removing the graft, wet gauze was compressed to the donor site by the surgeon for 60 seconds with moderate finger pressure. Then, the graft was sutured to de-epithelialized recipient site after adapting it to the tooth to be grafted. In the group A ( $n=5$ patients), the palatal wound was protected by a layer of AM and acrylic stent; conversely, group B patients $(n=5)$ covered only by non-eugenol pack and acrylic stent. Figures $1 \mathrm{a}-1 \mathrm{~d}$ and figures $2 \mathrm{a}-2 \mathrm{~d}$ show the healing on subsequent visits for test and control groups respectively.

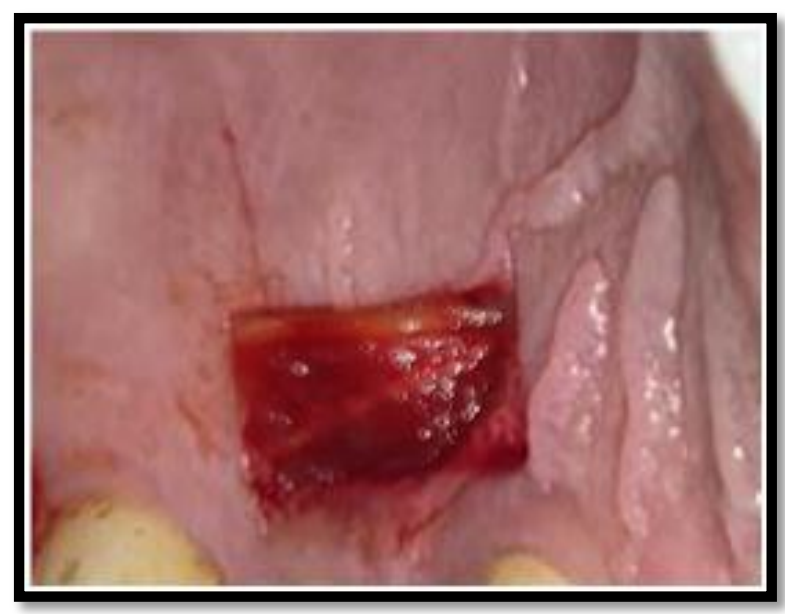

Fig-1a: Immediate post-operative view for group A

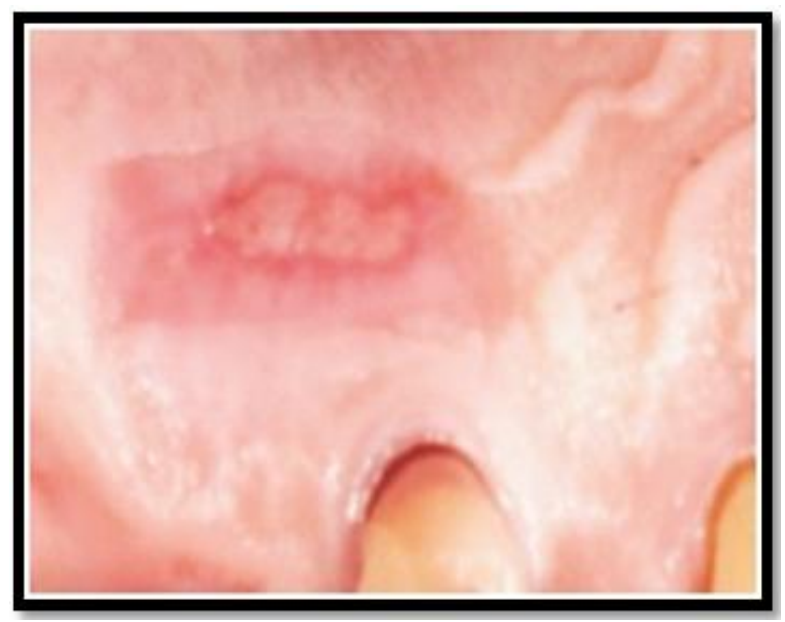

Fig-1b: One week post-operative view for group A

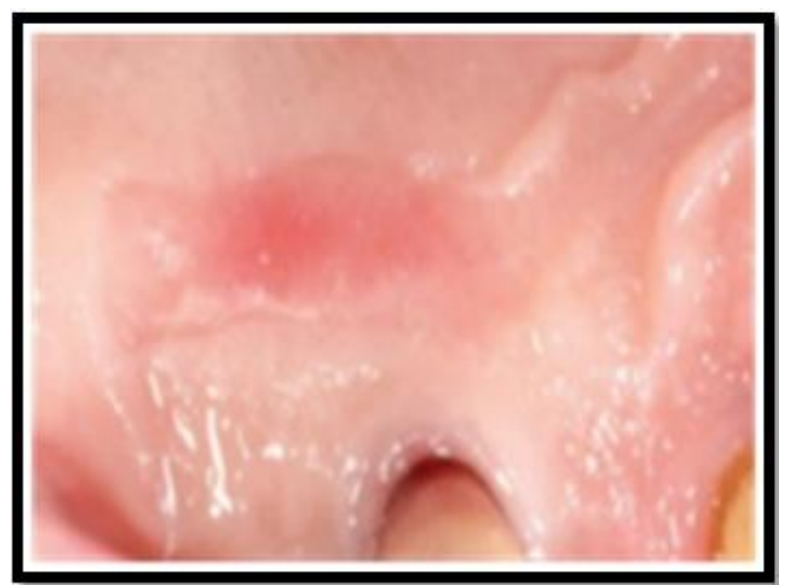

Fig-1c: Two weeks post-operative view for group A 


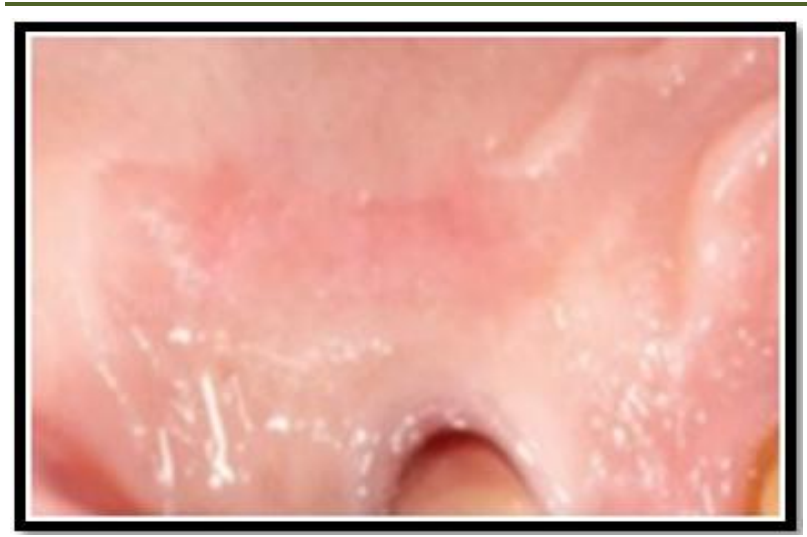

Fig-1d: Three weeks post-operative view for group A

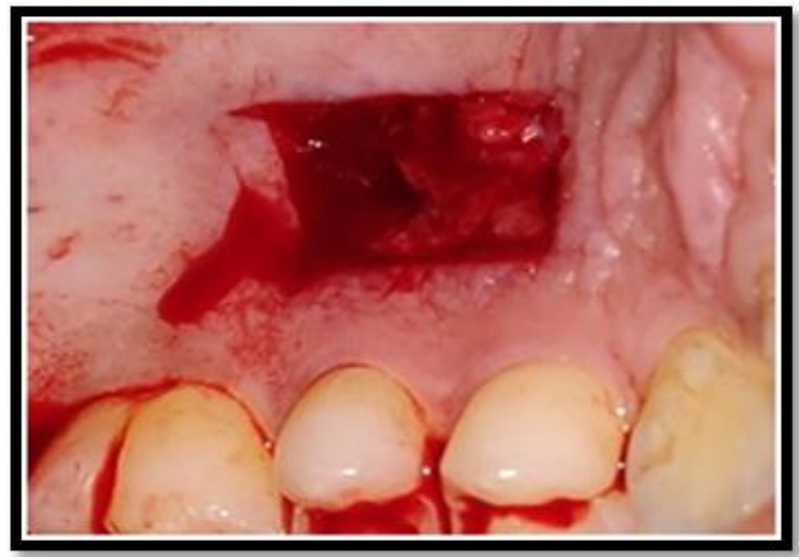

Fig-2a: Immediate post-operative view for group B

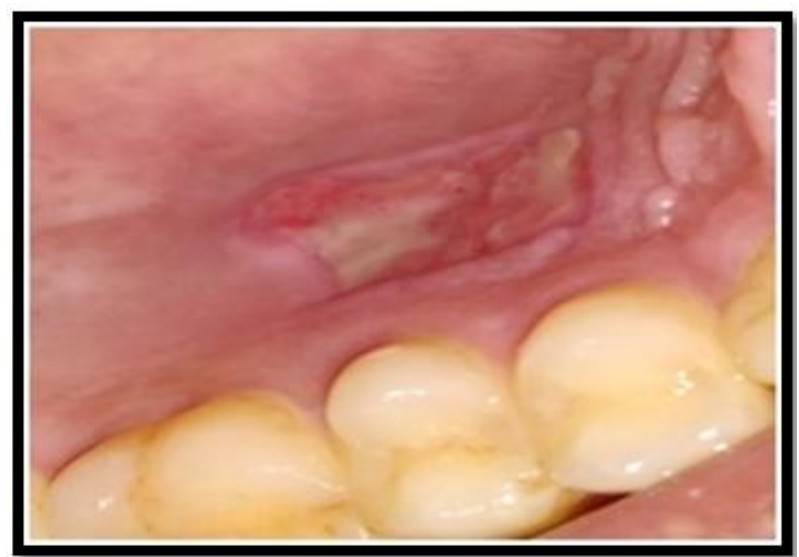

Fig-2b: One week post-operative view for group B

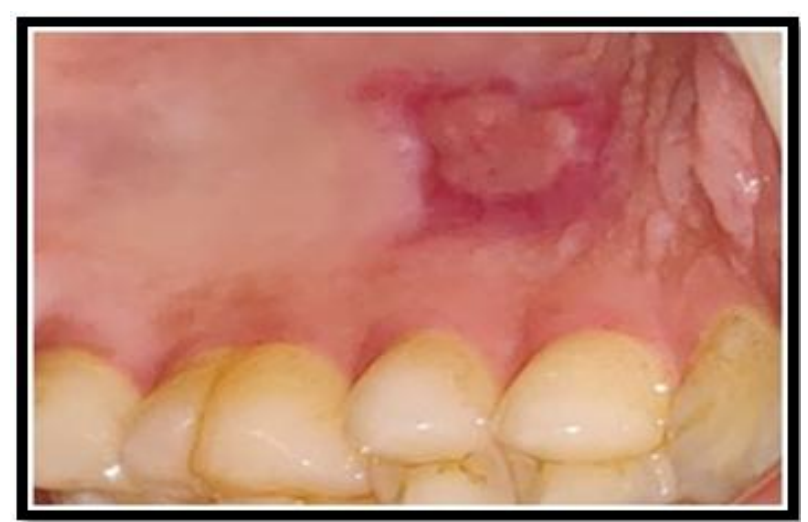

Fig-2c: Two weeks post-operative view for group B

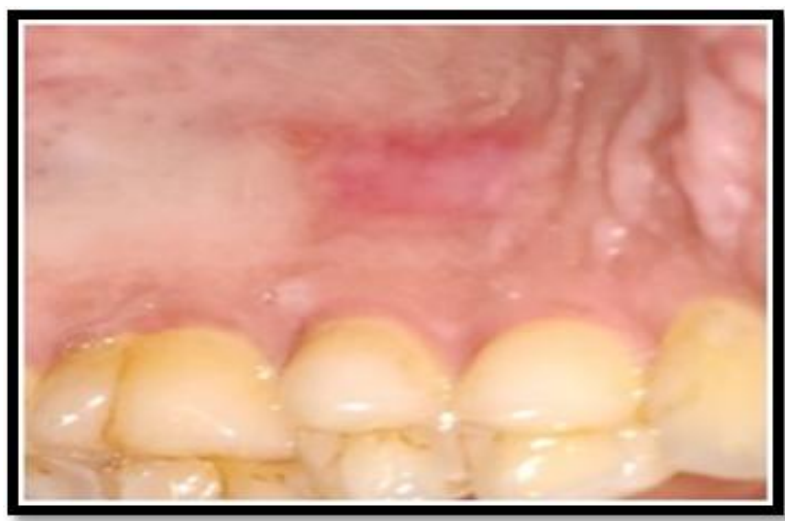

Fig-2d: Three weeks post-operative view for group B

\section{Postoperative care}

Immediately after the operation, participants were instructed to avoid eating and drinking acidic/hot. Antibiotics (Amoxicillin $500 \mathrm{mg}$ three times a day for five days) and anti-inflammatory analgesics (Diclofenac Sodium/Potassium-50 mg twice a day for 5 days) were prescribed. The patients were asked to use $0.2 \%$ Chlorhexidine Gluconate mouthwash twice daily for 2 weeks from the second day of surgery. Stent was discontinued after one week. Sutures at recipient area were removed after 2 weeks.

\section{Criteria and methodology to assess wound healing}

All patients were examined one, two and three weeks after surgery. The post-operative morbidity was assessed by asking patients to rate the post-operative pain on a Wong and Baker Faces Scale (WBFS) of 0-10. The value " 0 " represented "no pain or discomfort" and the value "10" represented "worst possible pain [7]". Marini Early Wound Healing Score (EHS) [8] was used for assessment of early stage of periodontal soft tissue wound healing. The EHS is composed of three parameters: clinical signs of re-epithelization (CSR), clinical signs of haemostasis (CSH), and clinical signs of inflammation (CSI). 0,3 , or 6 points were used to evaluate CSR, whereas 0,1 , or 2 points were used for both CSH and CSI. The EHS for ideal wound healing was 10 points, while the worst possible score was 0 points. An EHS of 0 points was assigned in the presence of suppuration, independently of the ratings for the three single parameters.

\section{STATISTICAL ANALYSIS}

Statistical analysis was performed using SPSS v20 software. Pain score and EHS scores among test and control groups were analyzed using independent $t$ test. Categorical data were analyzed using chi-square test. Statistics were considered significant if $\mathrm{P}$ value $<0.05$.

\section{RESULTS}

Total 10 patients aged 20 to 45 years were considered for the study. The gender distribution was not statistically different in the two groups. The mean age and standard deviation (SD) of the test group was $29.8 \pm$ 3.3 years, while for the control group, it was $30.4 \pm$ 
Nikita B. Rathi et al., Sch Acad J Biosci, Mar, 2021; 9(3): 98-102

4.1years. Neither age nor gender had a significant effect on pain scores and healing assessed in this study. All the ten enrolled patients completed the study without any dropouts in any of the postsurgical visits. Healing took place uneventfully with no patients reporting any adverse postoperative complications.

Patients were asked to rate the post-operative discomfort and pain on a WBFS of 0-10. The mean pain in the patients with Amniotic membrane dressings varied from $4.80 \pm 0.84$ to $3.20 \pm 0.84$ and then finally to $0.60 \pm$ 0.55 , respectively on first, second and third week post-operatively. The mean pain score of the patients without amniotic membrane dressings varied from 6.60 \pm 0.55 to $5.20 \pm 0.84$ and to $3 \pm 0.71$ respectively on first ,second and third week post- operatively (Table 1). The analysis revealed statistically significant difference between the test and control groups $(\mathrm{P}<0.05)$ with test group depicting less pain and discomfort when compared with control group at each week.

Table-1: Comparison of WBFS score for pain defined by patient on $1^{\text {st }}, 2^{\text {nd }}$ and $3^{\text {rd }}$ week post-surgically

\begin{tabular}{|l|l|l|l|l|l|}
\hline Week & Treatment & Control & Difference & t value & p value \\
\hline $\mathbf{1}$ & $4.80 \pm 0.84$ & $6.60 \pm 0.55$ & -1.80 & -4.025 & $0.004^{*}$ \\
\hline $\mathbf{2}$ & $3.20 \pm 0.84$ & $5.20 \pm 0.84$ & -2.00 & -3.78 & $0.005^{*}$ \\
\hline $\mathbf{3}$ & $0.60 \pm 0.55$ & $3 \pm 0.71$ & -2.40 & -6.00 & $0.001^{*}$ \\
\hline \multicolumn{6}{|c}{$*$ indicates significant difference at $\mathrm{p} \leq 0.05$}
\end{tabular}

Evaluation of palatal healing was performed by Early Wound Healing Score (EHS) by direct observation after surgery. On the evaluation of clinical signs of re-epithelialization, haemostasis and inflammation; statistically significant difference $(\mathrm{P}<0.05)$ for healing was observed among the two groups at each week, with test group showing better outcome as compared to control group (Table 2). However, on intragroup comparison of CSR, CSH and CSI, no significant difference for both test and control groups was observed at first, second and third week follow-up visits.

Table-2: Comparison of EHS for re-epithelialization, haemostasis and inflammation on $1^{\text {st }}, 2^{\text {nd }}$ and $3^{\text {rd }}$ week post-surgically

\begin{tabular}{|l|l|l|l|l|l|}
\hline Week & Test group & Control group & Difference & t value & p value \\
\hline $\mathbf{1}$ & $5.20 \pm 0.84$ & $3.20 \pm 1.64$ & 2.00 & 2.425 & $0.042^{*}$ \\
\hline $\mathbf{2}$ & $7.40 \pm 1.52$ & $5.00 \pm 1.23$ & 2.40 & 2.753 & $0.025^{*}$ \\
\hline $\mathbf{3}$ & $9.20 \pm 1.30$ & $7.00 \pm 1.23$ & 2.20 & 2.750 & $0.025^{*}$ \\
\hline \multicolumn{6}{|c}{} \\
\hline
\end{tabular}

\section{DISCUSSION}

FGG procurement procedure from palate causes surgical wound which heal by secondary intention. In the process of secondary healing, there may be several complications including secondary bleeding, delayed epithelialization and infections [9]. Therefore, dressing materials are used to protect the wound surface and to facilitate the healing process. The present study aimed to evaluate the effectiveness of AM on parameters related to patient's pain, discomfort and healing of palatal wound after FGG retrieval at different time intervals.

Amnion lines the inner most portion of the amniotic sac and is composed of three major layers: a single epithelial layer, a thick basement membrane, and an avascular mesenchyme consisting mainly of collagen [10]. Epithelial and mesenchymal cells express pluripotency and have the ability to differentiate to other cellular elements. Also, the mesenchymal stem cells (MSCs) show anti-inflammatory effect by decreasing production of various proinflammatory cytokines [11]. Basement membrane consists of collagen type IV and VII, laminin 1 and 5, fibronectin, and basic fibroblast growth factor (bFGF) [12]. Laminin-5, being the most prevalent in the amnion membrane helps in cellular adhesion of gingival cells, fibroblast growth and angiogenesis in the early phases of wound healing [11].

AM promotes epithelialization by facilitating migration, differentiation, prevention of apoptosis and sufficient oxygenation of epithelial cells [12]. Self adaptability and tight adherence of membrane helps in restoring lymphatic integrity, protects circulating phagocytes, allows faster removal of surface debris and bacteria from the wound [13]. All these above mentioned properties of the AM may be accountable for the better and faster closure of the palatal wound in the test group. These results could be in accordance with a study carried by Shah et al. where amnion membrane was used for recession coverage and complete coverage along with excellent esthetics and an improvement in gingival biotype was found [14].

Also, better pain control with test group was observed in present study as AM diminishes inflammation, provides a better state of hydration and protects the exposed nerve endings from external irritant [15]. Arai et al. evaluated the usefulness of the hyper-dry amniotic membrane as an intraoral wound dressing material for surgical defects of the oral mucosa and suggested that it could be an acceptable and suitable clinical alternative for the repair of the oral mucosa [16]. 
Nikita B. Rathi et al., Sch Acad J Biosci, Mar, 2021; 9(3): 98-102

In the present study, new score called EHS was used which has advantages over other indices like: following the healing process from very beginning, adequate and comprehensive inclusion of the clinical aspects of healing including independent assessment and subsequent integration of the different clinical aspects of primary healing [8]. On the other hand, in spite of self-adaptability and better handling properties, there is an associated risk of disease transmission with the Allograft membrane. Due to limited sample size, lack of histological, immunological and microbiological evaluation and short term follow-up; further studies will be required to establish and strengthen the fact of using $\mathrm{AM}$ as biologic dressing material for palatal healing.

\section{CONCLUSION}

AM as a biologic dressing may open new perspectives in the healing process. In view of the results of this study, AM did provide a faster and better haemostasis and made a positive contribution to the early soft tissue healing, reduced patient's post -operative pain and discomfort and thus, might be considered as a promising agent in accelerating the healing rate of the donor site and thus, developing postoperative comfort of the FGG harvested patients. AM possesses multiple biologic and physical characteristics, thus making it a better option over other conventional periodontal dressings.

\section{ACKNOWLEDGEMENTS}

The authors would like to thank the teaching and non-teaching staff of the department of Periodontology, VYWS Dental College and Hospital for the help they rendered for completion of this project.

\section{REFERENCES}

1. Sanz M, Simion M and Working Group 3 of the European Workshop on, P. Surgical techniques on periodontal plastic surgery and soft tissue regeneration: consensus report of Group 3 of the 10th European Workshop on Periodontology. J Clin Periodontol. 2014; 41:92-7.

2. Shah R, Thomas R, Mehta DS. Recent modifications of free gingival graft: A case series. Contemp Clin Dent. 2015; 6:425-7.

3. Uner DD, Izol BS. Evaluation of the effect of platelet-rich fibrin on palatal donor area pain after harvesting a free gingival graft. Int J Adv Res. 2018; 6:292-6.
4. Lafzi A, Farhani R. Amniotic membrane: A potential candidate for periodontal guided tissue regeneration?. Medical hypothesis. 2007; 69:454-73.

5. Koizumi N, Inatomi T, Sotozono C, Fullwood N J, Quantock A J, Kinoshita S. Growth factor mRNA and protein in preserved human amniotic membrane. Current Eye Research. 2000; 20:173-77.

6. Talmi YP, Sigler L, Inge E, Finkelstein Y, Zohar Y. Antibacterial Properties of Human Amniotic Membranes. Placenta. 1991; 12:285-88.

7. Wong DL, Baker CM. Pain in children: Comparison of assessment scales. Pediatr Nurs. 1988; 14:9- 17.

8. Marini L, Rojas MA, Sahrmann P, Aghazada R, Pilloni A. The Early Wound Healing Score (EHS): a system to evaluate the early healing of periodontal soft tissue wounds. J Periodontal Implant Sci. 2018; 48:274-83.

9. Alkan A and S Inal. Closure of palatal defects following excision of palatal pleomorphic adenomas. J Contemp Dent Pract. 2008; 9:99-107.

10. Chopra A and Thomas BS. Amniotic membrane: A novel material for regeneration and repair. J Biomim Biomater Tissue Eng. 2013; 18:106-13.

11. Parolini O, Alviano F, Bagnara GP, Bilic G, Buhring HJ, Evangelista M. Concise review: isolation and characterization of cells from human term placenta: outcome of the first international Workshop on Placenta Derived Stem Cells. Stem Cells. 2008; 26:300-11.

12. Gupta A, Kedige SD, Jain K. Amnion and chorion membranes: potential stem cell reservoir with wide applications in peridontics. Int $\mathrm{J}$ Biomater. 2015;1-9.

13. Rao TV and Chandrasekhram V. Use of dry human and bovine amnion as a biological dressing. Arch Surg. 1981; 116:891-6.

14. Shah R, Sowmya NK, Mehta DS. Amnion membrane for coverage of gingival recession: A novel application. Contemp Clic Dent. 2014; 5:293-5.

15. Rana MP, Mehrotra N. Human Amniotic Membrane: Hope in Periodontal Regeneration. Int J Sci Res. 2016; 5:564-9.

16. Arai N, Tsuno H, Okabe M, Yoshida T, Koike C, Noguchi M. Clinical application of a hyperdry amniotic membrane on surgical defects of the oral mucosa. J Oral Maxillofac Surg. 2012; 70:2221-8. 